\title{
An Analysis of Nonverbal Pragmatic Failure in Intercultural Communication
}

\author{
Wenjuan Du \\ School of Foreign Languages \\ Langfang Teachers University \\ Langfang, China \\ e-mail: 307894582@qq.com
}

\begin{abstract}
With the increasingly frequent intercultural communication, the influence of intercultural Pragmatic failures more and more clearly revealed. Currently, many researchers and language teachers at home and abroad conducted researches on verbal conduct pragmatic failure, but they often overlooked the nonverbal communication pragmatic failure. This paper focuses on the types and causes of nonverbal pragmatic failure in intercultural communication, and then puts forward the strategy to avoid or reduce pragmatic failures in order to provide some useful reference for people engaging in intercultural communication.
\end{abstract}

Keywords-nonverbal pragmatic failure; intercultural communication; causes

\section{INTRODUCTION}

In recent decades, with the advance of human technology, the process of globalization and information technology also will speed up, communication between different regions and cultures are becoming increasingly frequent, and cross-cultural communication in today's world has become a very important activity. However, due to different cultural backgrounds, cultural ideas communicators followed are not the same, which makes the emergence of pragmatic failure inevitable, and even there are misunderstandings and conflicts, largely affecting the smooth cross-cultural communication.

Jenny Thomas published an article titled "Cross-cultural Pragmatic Failure" in Applied Linguistics in 1983, in which he proposed the concept "pragmatic failure" for the first time , then many scholars discussed pragmatic failure.

So far, many domestic and foreign scholars and language teachers have conducted a lot of intensive research on verbal communication pragmatic failure, but they ignored another important aspect of communication, namely the nonverbal communication pragmatic failure. This article will explore nonverbal pragmatic failure from four aspects, to find out its causes, and then puts forward several strategies to avoid or reduce pragmatic failures in order to provide some useful reference for people engaging in intercultural communication.

\section{NonVerbal Pragmatic Failure}

Non-verbal communication covers a wide range, mainly referring to information generated by the common people and the environment except verbal information. Here the paper focuses on nonverbal communication which can best embody the cultural differences: body language, use of space, vice language and concept of time.

\section{A. Body Language}

Body language is that people use gestures, movements, and facial expressions and other means to convey non-verbal behavior information. Nodding, waving, raising one's eyebrows, and shrugging constituted the units of body language. In this area it includes eye language, tactile behavior, attitude, position, posture, gesture language, facial expressions and so on.

\section{1) Facial expressions}

People's facial expressions can show their rich inner emotions and can pass a lot of information. As a means of nonverbal communication, it is widely accepted. However, different cultural background also makes a difference of facial expression. For example, Han nationality greet their honored guests with smile when guests arrive; while American Indian tribe greet their guests with cry. Only understanding the different meanings of facial expressions in different cultures can avoid pragmatic failure of non-verbal behavior.

\section{2) Eye language}

There is a Chinese proverb "the eyes are the windows of the soul", so is in English-speaking countries. How can eyes express the soul? Because it has its own language-eye language. Eye language is an important means of communication, and its expressive function is extremely rich. However, due to the difference in cultures, the usage of eye language is not the same. Well-educated British men consider direct gaze into each other's eyes is a gentleman, but Chinese will feel uneasy if somebody else was watching him, primarily because of the sense of "shame". Eyes etiquette, all eyes gaze behavior and the function of eyes in communication reflect different cultural backgrounds and different cultural psychology.

\section{3) Sign language}

Sign language is an extremely complex body language, which is very important complementary human communication tool. It is used as a means of communication, and is the most 
used nonverbal behavior in communication. Body language should be restricted by cultural backgrounds. Different cultural backgrounds give different function to gestures. In China, circling the temple with a finger means racking one's brains; In America, it means driving one's crazy. Chinese people thumbing up means "good", and stretching out the little finger means "bad"; Americans express hitchhike by thumbing up, and express the "bad" by thumbing down.

There are many other forms of body language in crosscultural communication, such as touching, hugging, standing, etc., which I will not dwell on the details. In short, the information of body language is extremely rich, far beyond our imagination, but it also has its limitations, namely restriction of cultural backgrounds.

\section{B. Space Utilization}

Proxemics is a very important component of nonverbal communication. Spatial behavior is the method of people dealing with spatial relations, including body contact, visual behavior and touch behavior. Cultural background is different, so the method to process spatial relationships is different. Next, the author will analyze the misunderstanding and cultural conflict of two different space systems.

\section{1) Body contact}

Body contact is a major spatial behavior. How to interpret its meaning has great differences between China and U.S. Interaction between people requires a certain distance. Space communicative distance of Americans can be divided into four areas: intimate area, acquaintances area, social area and public occasions.

Intimate Area: from direct physical contact to 45 centimeters.

Acquaintances Area: usually between $45-80 \mathrm{~cm}$.

Social area: generally between 1.30 to 2 meters.

Public occasions: generally above 2 meters.

The spatial relationship of the Chinese people during the speech: the distance of personal conversation between friends or acquaintances is from 0.5 to $1 \mathrm{~m}$; the distance of general social activities is about $1.5 \mathrm{~m}$; the distance of speech to the crowd is more than three meters.

Americans generally avoid body contact with unintimate people, while Chinese people are accustomed to short, light body contact. Therefore, some Americans consider that the Chinese people are more polite in private, but in public places we are very bold, rude. This misconception stems from the different attitudes to body touch between Chinese and Americans.

\section{2) Touch}

Touch is an important way of spatial behavior. Touch, for the Chinese people, is a friendly behavior. For example, we will touch the lovely children. But Americans usually avoid touching behavior, except in intimate relationships. American mothers in China often complain about their children fondled by Chinese friends or acquaintances and feel it is offensive.

\section{3) Visual behavior}

In public, Chinese people usually stare at some strange and admirable people or things, while the Americans loathe this behavior. A beautiful young American woman in China complained: "I feel embarrassed to be watched in public places. Some pedestrians passing me glance me which makes me feel that I am not a person, but an animal or a thing." Many Americans in China consider such behavior is "unpolite" and "rude".

In short, all cross-cultural conflicts are caused due to cultural differences, which prompts us to further study different concepts of space and space requirements between Chinese and American cultures.

\section{Paralanguage}

Paralanguage has narrow and broad senses. Paralanguage in narrow sense refers to the sound phenomena, such as speaking out of breath, stammering, incoherent speaking. These are accompanied by the occurrence or impact on discourse, which have some meanings, but that kind of meanings do not come from the vocabulary, grammar rules or general rule of pronunciation. Paralanguage in broad sense refers to silent but tangible phenomenon, that is, gestures, facial expressions, position and distance in conversation, etc., used simultaneously or separately with words, which can also express a certain sense.

The Chinese and American cultural backgrounds are different, but the meanings of some paralanguage knowledge are shared. Some are quite different, even have completely opposite meaning. For example, Chinese people express good, approval and some meanings like that with thumbs up, and the Britain and Americans are similar at this point. In expressing figures " 0 to 10 ", Chinese people only use five fingers of one hand, but the American people will use both hands in expressing figures more than " 5 ". This is not to say that the former is smarter than the latter, but for different ethnic habit.

Chinese people and the people in English-speaking countries treat silence in different ways. For a good thing, when both the Chinese and the Americans want to get it, the Americans will speak out their ideas directly, but Chinese people will prefer the silent way to express the same wish. Because in Chinese culture, silence is gold, is a virtue, often representing consent willing. In the eyes of the American people, "silence" is precisely to say "No". When the Americans talking to the Chinese, sometimes they feel puzzled with silence of the Chinese. In this case, Americans tend to think that Chinese people do not understand them, and they will repeat what he said. In fact, he does not understand maybe Chinese people are transferring some unspeakable emotion or information. This pragmatic failure phenomenon, is caused by cultural differences between the two sides.

Paralanguage is an integral part of human communication activities, a necessary complement to verbal communication. It has a special communicative function, and it plays a complementary role in the significance of discourse. Thus, in communication, only paying more attention to the complementary role of verbal communication and nonverbal communication and using the paralanguage to modify 
discourse can promote a more harmonious and smooth communication.

\section{Concept of Time}

Concept of time as one of the elements of nonverbal communication has a great impact on intercultural communication. Concept of time is naturally formed in social practice. People from different cultural backgrounds have different practicing, ways of thinking, approach to processing and arranging the time. In other words, cultural background is different, then the concept of time is also different. Here's to compare the difference of time concept between China and the U.S..

Concept of time reflects the usage of the time in a culture, thus reflecting the cultural characteristics. In China, people focus on tradition. "Past things are the teacher of the future". Chinese people believe the past can become a de facto standard for decision-making and judgment. "Past-oriented" concept of time has affected the Chinese people's behavior and way of thinking. Americans always pay attention to what is about to happen in front. This is because in the United States Christianity occupied the dominance, and Christianity tells people: people born in this evil earth are to suffer, only God can rescue people, and they can hope to have a future only by going ahead. Therefore, this contributed to the "future" concept of time of Americans.

American anthropologist Edward Hall divided the concept of time into two categories: "monochromic time" and "polychronic time". Monochromic time thinks that time is a straight line, just like computer serial working mode. So it is characterized by emphasis on schedule, stage time and punctuality. Polychronic time is characterized by several events going simultaneously, just like computer time-sharing mode, which features flexible. Chinese people can be classified into people who follow polychronic time, while the American concept of time belongs to pursue monochromic time that can be separated by time, but not duplicate, based on regular intervals to complete the continuity of events. It determines that the Americans pay much attention to time, so reservation has become an indispensable practice in American culture. The Chinese people's concept of time is a "timely concept", "timesharing concept", that is to say, when necessary, we will adjust time according to our needs, and we can do multiple things simultaneously. So Chinese people use time more flexibly.

Here we compare concept of time in Chinese culture and American culture, with the aim to get people to understand different cultural attitudes and different ways to use time, to know ourselves, to understand each other, and to respect each other. When the conflict occurs, both sides should take a tolerant attitude, to ensure the smooth cross-cultural communication.

\section{THE CAUSES OF PRAGMATIC FAILURES}

The author analyzed some performance of pragmatic failure, through the analysis, it can be seen that cross-cultural pragmatic failure was caused by a number of factors. There are language mistakes and cultural differences, but the failures caused by cultural differences accounted for a dominant reign.
People from different cultural backgrounds have great difference in terms of values, morals, customs, beliefs, ways of thinking and so on, which resulted in a diversity of pragmatic failures. In addition, cultural migration and cultural prejudices of communicators in cultural communication process are also the causes of pragmatic failures. Here, we will make some simple analysis of the reasons.

\section{A. Differences in Religious Beliefs}

Religious belief refers to unshakable conviction and the conversion of heart and soul of people who profess a particular religion to the sacred object (including the specific teachings and doctrines, etc.). This faith and conversion of heart and soul performs in specific rituals and religious activities, and is used to guide and regulate their own behavior in a secular society. It belongs to a particular social ideologies and cultural phenomenon.

Religion is an important part of human thought. Ethnic groups are different, then religious and cultural beliefs are different. The Chinese and Americans have great difference in religious terms. Almost all Americans have the same belief and almost the same religion-Christianity, which includes a variety of Christian denominations, such as Catholic, Protestant and Orthodox. As America's main religion, Christianity is deeply implanted into the American culture. Its values, outlook on life, and concept of time all with Christian -defined brand. So, in American culture, some of the idioms and proverbs are also concerned with God, such as "God sends fortune to fools", "God bless you!" American presidents selected their favorite Bible version in his inaugural ceremony, and put theirs hands on the Bible to take their oath "to govern the country with biblical principles". The characters and the stories in the Bible after a long time of spread are known to every family and has become an important source of English idioms. It has been associated with the English language. Some people even said, if you do not understand the Bible, you will not understand Western culture. In China, only a few people have religious beliefs, and the vast majority of people haven't or don't know if he has or not. Among the religious people, there are a large number of Christians, but the main religious factions are Buddhism, Islam and Taoism. Since the introduction of Buddhism to China, its influence is the greatest, and its ideological doctrine influences the Chinese people deeply and is implanted into the Chinese culture. Its influence on the Chinese language vocabulary can not be underestimated. A considerable number of words come from the Buddhism thought, such as “来世今生”、”半路出家”、“放下屠刀，立 地成佛” and so on. If these words are translated into English literally, the Americans will not understand. On the other hand, if people do not understand the Bible, they can not really understand American culture.

\section{B. Differences in Ways of Thinking}

Way of thinking dominates a person's words and deeds, and it is the inherent pattern of brain activity. Way of thinking is relatively finalized, and it has a custom-oriented, traditionaloriented features in the thinking pattern and thinking structure in the social rational activities. It penetrates into various areas of people's lives, emotional and behavioral methods, and 
guides and restricts people's words and deeds. Way of thinking also has a relative variability. Cultural backgrounds are different, it will varies widely. The interference caused by differences in ways of thinking is the important reason for pragmatic failures in intercultural communication.

Chinese people's thinking pays attention to psychological time and space, and emphasizes time. Chinese people's way of thinking mainly emphasizes image thinking, and its feature is the overall unity. While the Americans pay attention to the natural temporal and spatial thinking, and its emphasis is on natural authenticity in space. This feature is related to the combination of philosophy and science and technology of the early Europeans and Americans.Two modes of thinking are reflected in the syntactic level: Chinese is time-based structure, emphasizing the free and direct expression. Various grammatical relationship is expressed in word order and function words. Sentence structure is simple and casual. Some Chinese sentence elements are often omitted, which is a way of thinking reflected in Chinese. English is space-based structure, emphasizing rigor and indirect expression. In order to ensure the integrity of the form, English sentence elements are generally not omitted.

In summary, the different ways of thinking created a different language structure model. In cross-cultural communication, pragmatic failures tend to be caused by their ways of thinking as a standard to communicate of the two parties, which leads to misunderstanding each other. To make the message recipient clearly understand the willingness to express themselves not only is related to the accuracy of the information available, but also should pay attention to organize the information conforming to their ways of thinking.

\section{Differences in Values}

Value refers to the total evaluation and overall views on the meaning and importance of the objective things around a person (including people, things, and objects). Value is reflected in people's social existence, and is used as a standard by social members to evaluate the behaviors or things. Value is the core of culture, and language is the carrier of culture. In inter-cultural communication, if one does not understand the values of a nation, then he will not be able to understand the the nation's culture, thus the communication is impossible.

US scholar Larry A.Samovar put forward the difference between Chinese and Western cultural values in his book Intercultural Communication: the eastern cultures attach great importance to collectivism, while the western cultures is based on individualism. China and America are two typical representatives of cultural values.

Collectivism refers to the interest of the community, the society and the country has always been given top priority, while that of the locality, the part or the individual is sometimes ignored.an individual's value can be realized only within society as a whole, as that is the groundwork of one's existence. So Chinese culture is also known as "I-less culture".

Western cultural value is individualism. It is based on a market economy and capitalist relations of production. It is an individual standard of value. It emphasizes personal values, interests and dignity. Self-realization and self-development and even personal time and space have become its very strong and prominent feature.

\section{SUMMARY}

Bi Jiwan once pointed out that: "in the process of intercultural communication, nonverbal communication is an indispensable part of the whole communication. Only paying attention to verbal communication but ignoring non-verbal communication is only an incomplete communication; only talking about body language but ignoring other aspects of nonverbal communicative behavior is one-sided; non-verbal communication also has strong culture characteristics, so ignoring the cultural difference of nonverbal communication will have serious consequences."

There are a lot of cultural differences in the way of thinking, values, beliefs and customs, etc. in Chinese and western cultures, which are the main cause of communicative pragmatic failure. In order to achieve successful communication to the maximum extent, the two communicative parties should exclude the sense of cultural superiority, cultural prejudice, and stereotypes, to reduce the possibility of cultural conflict.

\section{REFERENCES}

[1] Zhang Licai and Liu Xin, "An Analysis of Pragmatic Failure in Crosscultural Communication and the Countermeasures," Journal of Language and Literature Studies, vol. 2, 2009, pp. 9-14.

[2] Thomas L. Warren, Cross-Cultural Communication: Perspectives in Theory and Practice, Baywood Publication, 2006..

[3] William B. Gudykunst, Cross-Cultural and Intercultural Communication, SAGE Publications, 2003.

[4] Larry A. Samovar, Richard E. Porter, Intercultural Communication, Wadsworth Publication Company, 1997.

[5] Thomas, J., Cross-Cultural Pragmatic Failure. Applied Linguistics, 1983

[6] Chen Zhiyi, "Pragmatic Analysis of Problems in Cross-cultural Communication", Rean and Write Periodical, Vol. 7, No. 6, 2010, pp. 1-3.

[7] Samovar, L.A. and R.E.Porter, Communication between Cultures, Belmont, Albany: Wadsworth Publishing Company, 2001.

[8] Bi Jiwan., Cross-Cultural Noverbal Communication. Beijing: Foreign Language Teaching and Research Press, 1999. 